\title{
Glycerine Treated Nanofibrillated Cellulose Composites
}

\author{
Esra Erbas Kiziltas, ${ }^{1,2}$ Alper Kiziltas, ${ }^{1,3}$ Behzad Nazari, ${ }^{4}$ \\ Douglas J. Gardner, ${ }^{1}$ and Douglas W. Bousfield ${ }^{4}$ \\ ${ }^{1}$ Advanced Structures and Composites Center, University of Maine, Orono, ME 04469, USA \\ ${ }^{2}$ The Scientific and Technological Research Council of Turkey (TÜBİTAK), Tunus Caddesi, Kavaklidere, 06100 Ankara, Turkey \\ ${ }^{3}$ Department of Forest Industry Engineering, Faculty of Forestry, University of Bartin, 74100 Bartın, Turkey \\ ${ }^{4}$ Department of Chemical Engineering, University of Maine, Orono, ME 04469, USA
}

Correspondence should be addressed to Esra Erbas Kiziltas; esrabiyo@hotmail.com

Received 20 January 2016; Revised 14 March 2016; Accepted 28 March 2016

Academic Editor: Wanshuang Liu

Copyright (C) 2016 Esra Erbas Kiziltas et al. This is an open access article distributed under the Creative Commons Attribution License, which permits unrestricted use, distribution, and reproduction in any medium, provided the original work is properly cited.

Glycerine treated nanofibrillated cellulose (GNFC) was prepared by mixing aqueous nanofibrillated cellulose (NFC) suspensions with glycerine. Styrene maleic anhydride (SMA) copolymer composites with different loadings of GNFC were prepared by melt compounding followed by injection molding. The incorporation of GNFC increased tensile and flexural modulus of elasticity of the composites. Thermogravimetric analysis showed that as GNFC loading increased, the thermal stability of the composites decreased marginally. The incorporation of GNFC into the SMA copolymer matrix resulted in higher elastic modulus $\left(G^{\prime}\right)$ and shear viscosities than the neat SMA copolymer, especially at low frequencies. The orientation of rigid GNFC particles in the composites induced a strong shear thinning behavior with an increase in GNFC loading. The decrease in the slope of elastic modulus with increasing GNFC loading suggested that the microstructural changes of the polymer matrix can be attributed to the incorporation of GNFC. Scanning electron microscopy (SEM) images of fracture surfaces show areas of GNFC agglomerates in the SMA matrix.

\section{Introduction}

In the past twenty years, much attention has been devoted to the study and development of polymer nanocomposites using various nanofillers including clay, silica, carbon nanotubes, and cellulose nanofibers $[1,2]$. Recent years, in particular, have seen a large global interest regarding cellulose nanocomposites. National and international meetings of the Organization for Economic Cooperation and Development, Society of Wood Science Technology, Forest Products Society, American Chemical Society, and Technical Association of the Pulp and Paper Industry have covered the subject of cellulose nanocomposites. Interest throughout the last decade in the subject has also led to an increase in the number of publications on the preparation of cellulose nanofiber reinforced composites (including nanofibrillated cellulose (NFC), microfibrillated cellulose (MFC), cellulose nanocrystals (CNC), bacterial cellulose (BC), and electrospun cellulose nanofibers $(\mathrm{ECN})$ ). Interest is also reflected through the increasing number of review papers which provide detailed information on the production of cellulose nanofibers, processing, and characterization of cellulose nanocomposites and new developments, with particular emphasis on their applications [3-12].

Because of its unique properties, NFC has received considerable attention for the preparation of green nanocomposites with polymer matrices. Such properties include high strength, high stiffness, low density when compared to glass fibers, ease of chemical modification attributable to a natural advantage of an abundance of hydroxyl groups on the surface of NFC, and biodegradability [3, 13-16]. The potential benefits associated with NFC have been confirmed; however, uniform dispersion of NFC remains a challenge in exploiting the exceptional properties of NFC [17]. To improve the compatibility at the fiber-matrix interface and dispersion of NFC, various methods have been adopted, including the use of surfactants, functionalization of NFC, and the use of carrier systems in NFC-polymer nanocomposites $[15,16,18-$ $25]$. One of the main challenges to address is the stability of NFCs in suspension, which is a difficult impediment to 


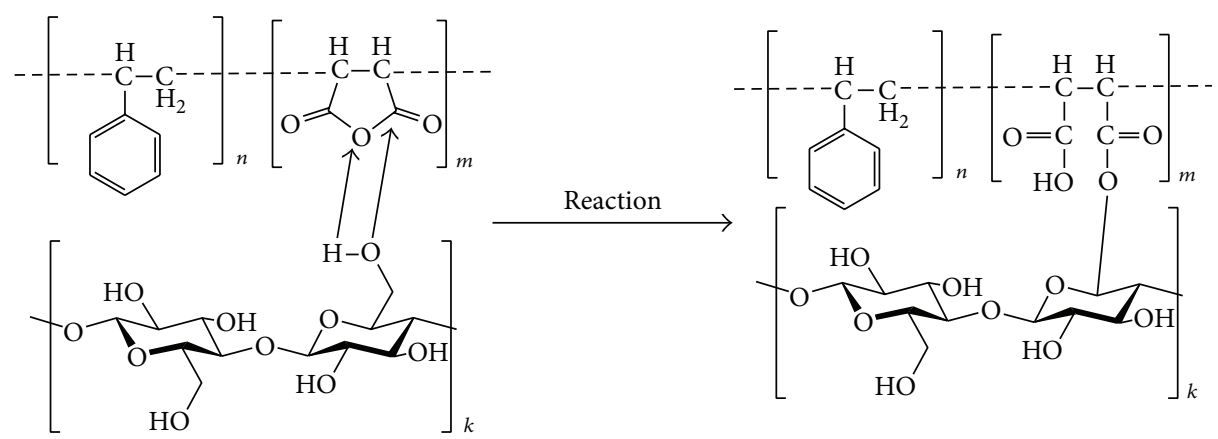

FIGURE 1: Schematic representation of the interfacial reaction between SMA copolymer and nanofibrillated cellulose (NFC).

overcome because of NFCs' high surface energy and the large number of hydrogen bonds that can be formed among NFCs $[3,16]$. NFCs can agglomerate leading to gel formation which negatively impacts the mixing properties of such suspensions in polymer matrices. The desulfonation of CNC with glycerol has been reported by Dorris and Gray [26], but, to the best of our knowledge, formation of a stable NFC suspension in glycerine by mixing aqueous suspensions of NFC with glycerine has not yet been reported in literature.

Styrene-malic anhydride (SMA), which has higher glass transition temperature $\left(T_{g}\right)$ and heat deflection temperature (HDT) than most commodity plastics, is an engineering thermoplastic copolymer and both unfilled and glass-filled SMA are used extensively in the automobile industry for both injection molding and thermoforming of interior parts [27-29]. Because of its simplicity, applicability for industrial composite production, and reactive functional groups, SMA copolymers are also used as compatibilizing agents, which reduce the initial interphase incompatibility, in carbon nanotube reinforced polyamide 12 (PA12) and polyvinyl chloride (PVC) nanocomposites [30-32]. To the best of our knowledge, we are the first to examine the properties of NFC dispersed in a SMA copolymer matrix prepared by melt compounding followed by injection molding. The maleic anhydride group on the polymer backbone reacts with hydroxyl groups on the NFC. The modified NFC surfaces and SMA copolymer composites will be characterized in detail by elemental analysis, contact angle measurements, inverse gas chromatography, X-ray photoelectron, and infrared spectroscopy in our next publications. The reaction is depicted schematically in Figure 1.

Despite the technological interest in SMA copolymers, only a few studies of filled-SMA copolymer composites have been reported [27, 28, 33-36]. Simonsen et al. showed that the mechanical properties of recycled newsprint-filled SMA copolymer were higher than those of unfilled plastics but lower than those of wood fiber-filled SMA copolymers [27]. Chrysostomou and Hashemi investigated the dependence of mechanical and fracture properties of SMA copolymer on volume fraction of glass fibers. Their results indicated that the addition of glass fibers enhances tensile and flexural strengths of the SMA matrix [33]. Moreover, Michalik and coworkers claimed a novel method for making foamed cellulosic fiberSMA copolymer thermoplastic composites. They reported that foamed cellulosic fiber-SMA copolymer thermoplastic composites showed superior tensile and thermal properties to wood fiber and/or wood flour-filled polyolefins composites [36]. Earlier SMA studies were concerned with mechanical and morphological properties and there is lack of information related to rheological properties of SMA copolymer composites in the literature. In this paper, the rheological properties of SMA copolymer composites with different glycerine treated NFC loadings are also systematically studied to investigate the effect of glycerine treated NFC on the rheological properties of the SMA copolymer matrix.

It is hypothesized that the incorporation of glycerine treated NFC (GNFC) into SMA copolymer should lead to an enhancement of composite mechanical properties. However, the interactions of hydrophilic NFC with hydrophilic polymer chains and glycerine are likely to be complex. Glycerine can act as a plasticizer which can reduce the mechanical properties of the composite materials and the addition of glycerine can also decrease the thermal stability of NFC, limiting its reinforcing efficiency in SMA copolymer composites with high processing temperatures. In this paper, the properties and structure of SMA copolymer composites containing GNFC relative to neat SMA are examined.

\section{Experimental}

2.1. Materials and Gel Preparation or Treatment of NFC. NOVA chemical company (Pittsburgh, PA) kindly supplied SMA copolymer, Dylark 232 (SMA-7), which contained 7\% maleic anhydride. The lubricant (Struktol TPW 113), processing aid, was kindly supplied by Struktol Company with a specific gravity of 1.005 and dropping point of $67-77^{\circ} \mathrm{C}$. NFC with diameters $20-50 \mathrm{~nm}$ and lengths over a micron was produced mechanically from a bleached softwood kraft pulp fiber using refining or homogenization at a $3.5 \mathrm{wt} \%$ solids content. The G5150 glycerine (99\% purity) was purchased from Sigma Aldrich Co., USA, and used as received. Gels or glycerine treated cellulose (GNFC) was prepared by mixing aqueous NFC suspensions with glycerine. The premixture containing NFC and glycerine (10/1 by wt. ratio) was stirred vigorously with a high speed rotor stator mixer (Kady Mill) for $30 \mathrm{~min}$ to achieve suspension homogeneity. Prior to freeze drying, GNFC suspensions (about $100 \mathrm{~mL}$ ) were frozen in vials at a temperature of $-80^{\circ} \mathrm{C}$ for $24 \mathrm{~h}$. 
TABLE 1: Composition of SMA copolymer and GNFC composites.

\begin{tabular}{lccc}
\hline Sample code & GNFC content & SMA copolymer & Lubricant \\
\hline SMA & 0 & 100 & 0 \\
SMA+L & 0 & 97 & 3 \\
$2.5 \%$ GNFC & 2.5 & 94.5 & 3 \\
$5 \%$ GNFC & 5 & 92 & 3 \\
$10 \%$ GNFC & 10 & 87 & 3 \\
\hline
\end{tabular}

Values are percentage by weight (wt.\%).

2.2. Processing of Composite Materials. The SMA-GNFC compounding was conducted using a Brabender PrepMixer ${ }^{\circledR}$ and the temperature was set to $240^{\circ} \mathrm{C}$ and rotor speed at $60 \mathrm{rpm}$. NFC was added to the mixer when the polymer melt appeared visually well mixed. The processing temperature and NFC residence times, approximately three minutes, were recognized as a relatively safe temperature range to prevent thermal degradation. The mixing process was completed in $10 \mathrm{~min}$ until torque of the mixture stabilized. All materials were injection-molded using a barrel temperature of $240^{\circ} \mathrm{C}$, mold temperature of $240^{\circ} \mathrm{C}$, and injection pressure of $17 \mathrm{MPa}$. The details of sample preparation and processing of composite materials can be found in Kiziltas et al. 2014 [37]. The compositions of the SMA-GNFC composites are shown in Table 1.

\subsection{Characterization}

2.3.1. Mechanical Testing. Tension and flexure tests were conducted according to the American Society of Testing and Materials (ASTM) standard D 638-03 and ASTM D 790-03, Test Method 1, and Procedure A, respectively. The details of these testing methods can be found in Aydemir et al. [38].

2.3.2. Thermogravimetric Analysis (TGA). TGA measurements were performed using a Mettler Toledo analyzer. Each $10 \mathrm{mg}$ sample was scanned from room temperature to $600^{\circ} \mathrm{C}$ at a heating rate of $10^{\circ} \mathrm{C} / \mathrm{min}$ under nitrogen flow $(20 \mathrm{~mL} / \mathrm{min})$ to prevent sample oxidation. Five random samples were chosen for the TGA measurements from the ground test specimens. To eliminate the buoyancy effect, experiments were repeated with an empty sample pan and a baseline was thus obtained.

2.3.3. Rheological Measurements. Rheological properties of the SMA copolymer and GNFC composites were measured on a stress-controlled Bohlin Gemini rheometer (Malvern Instruments, UK) at a temperature of $240^{\circ} \mathrm{C}$. Small-amplitude oscillatory shear measurements were performed using a parallel plate geometry with a plate diameter of $25 \mathrm{~mm}$ and a plate gap of $1.0 \mathrm{~mm}$ to acquire the elastic moduli $\left(G^{\prime}\right)$, the loss moduli $\left(G^{\prime \prime}\right)$, and the loss factor $(\tan \delta)$. Steady rate sweep tests were also performed at a low shear rate range to obtain the apparent viscosities $(\eta)$ of the SMA copolymer and GNFC composites. To maintain the rheological measurements in the linear viscoelastic region, strain sweeps were performed in advance for each sample, and consequently, a strain of
$1 \%$ was selected for all frequencies $(0.01-100 \mathrm{~Hz})$. The melt flow behavior of the composites was also studied using a conventional melt flow index (MFI) tester at a temperature of $240^{\circ} \mathrm{C}$ and the details of MFI testing can be found in Aydemir et al. [39].

2.3.4. Scanning Electron Microscopy. Scanning electron microscopy (SEM) was used to observe the dispersion of the GNFC in the SMA copolymer matrix and the quality of the interfaces between the GNFC and SMA copolymer matrix. More detailed information about SEM analysis can be found in Ozen et al. [40].

2.4. Statistical Analysis. The tensile and flexural properties and MFI values were evaluated using a one-way analysis of variance followed by Tukey-Kramer Honestly Significant Differences (HSD) test using a JMP statistical analysis program (JMP) [41].

\section{Results and Discussion}

3.1. Mechanical Properties. The mechanical properties of the composites are presented in Table 2. It was observed that the neat SMA copolymer exhibits nonlinear elastic behavior with a tensile strength of $45.7 \mathrm{MPa}$ and an elongation at break of $2.3 \%$. The GNFC reinforced composite displayed significantly lower tensile strength (10 wt.\% GNFC content, decreased $10.3 \%$ ) in comparison with the neat SMA copolymer. Two potential explanations are offered for this finding: (1) poor interfacial bonding between GNFC and the SMA copolymer and (2) the existence of the cellulose nanofibrils, as an obstruction, separating the molecular chains of the SMA copolymer, which makes the distance among the molecules larger and the force among the molecular chains of SMA copolymer weaker $[42,43]$. Glycerol can decrease mechanical properties by lowering the strength of the composites because of its plasticizing effect [43]. In Table 2, elongation at break of the composites was lower (decreasing values from 2.3 to $1.2 \%$ with the addition of $10 \mathrm{wt} . \%$ GNFC). The tensile modulus of elasticity (TMOE) of GNFC composites increased noticeably with increased GNFC loading (attaining values from 3.1 to 3.6 GPa with the addition of $10 \mathrm{wt} \% \mathrm{GNFC)}$ ) attributable to the high modulus of GNFC.

In Table 2, the average values of flexural strength of the neat SMA copolymer and GNFC composites are shown. The flexural strength of neat SMA copolymer is $85.5 \mathrm{MPa}$ and incorporation of GNFC significantly reduced flexural strength (10wt.\% GNFC content, decreased 18.9\%). The decrease in flexural strength can be explained by the same explanations presented for the observed reduced tensile strength of the composites. As can be seen in Table 2, the flexural modulus of elasticity of composites was higher than that of the neat SMA copolymer. Similar to TMOE, the flexural modulus of elasticity (FMOE) also increased with increasing GNFC loading (reaching values from 3.0 to $3.4 \mathrm{GPa}$ with the addition of $10 \mathrm{wt} \% \mathrm{GNFC)}$. It can be concluded that FMOE and TMOE of GNFC-filled composites 
TABLE 2: Mechanical properties and melt flow index (MFI) of SMA copolymer and GNFC composites.

\begin{tabular}{|c|c|c|c|c|c|}
\hline Sample code & SMA & SMA+L & $2.5 \%$ GNFC & $5 \%$ GNFC & $10 \%$ GNFC \\
\hline Tensile strength $(\mathrm{MPa})$ & $45.3(1.8)^{\mathrm{A}}$ & $41.4(1.6)^{\mathrm{B}}$ & $45.4(1.9)^{\mathrm{A}}$ & $43.7(2.9)^{\mathrm{AB}}$ & $40.7(2.4)^{\mathrm{B}}$ \\
\hline TMOE $(\mathrm{GPa})$ & $3.1(0.1)^{\mathrm{C}}$ & $3.1(0.1)^{\mathrm{C}}$ & $3.3(0.1)^{\mathrm{B}}$ & $3.3(0.1)^{\mathrm{B}}$ & $3.6(0.1)^{\mathrm{A}}$ \\
\hline $\mathrm{EAB}(\%)$ & $2.3(0.2)^{\mathrm{B}}$ & $3.1(0.5)^{\mathrm{A}}$ & $1.8(0.2)^{\mathrm{C}}$ & $1.7(0.2)^{\mathrm{CD}}$ & $1.2(0.2)^{\mathrm{D}}$ \\
\hline Flexural strength $(\mathrm{MPa})$ & $85.5(3.1)^{\mathrm{A}}$ & $82.2(3.0)^{\mathrm{AB}}$ & $79.9(4.9)^{\mathrm{AB}}$ & $77.8(3.3)^{\mathrm{B}}$ & $69.4(3.7)^{\mathrm{C}}$ \\
\hline FMOE $(\mathrm{GPa})$ & $3.0(0.1)^{\mathrm{C}}$ & $3.0(0.1)^{\mathrm{C}}$ & $3.3(0.1)^{\mathrm{B}}$ & $3.2(0.1)^{\mathrm{B}}$ & $3.4(0.1)^{\mathrm{A}}$ \\
\hline MFI (g/10 min) & $5.1(0.5)^{\mathrm{B}}$ & $5.9(0.5)^{\mathrm{A}}$ & $4.2(0.5)^{\mathrm{C}}$ & $2.1(0.4)$ & $0.3(0.1)^{\mathrm{E}}$ \\
\hline
\end{tabular}

Parenthesis indicates standard deviation and the same letters indicate no statistical difference between properties of composites and those around it $(\alpha=0.05)$. FMOE: flexural modulus of elasticity; TMOE: tensile modulus of elasticity; EAB: elongation at break; and MFI: melt flow index.

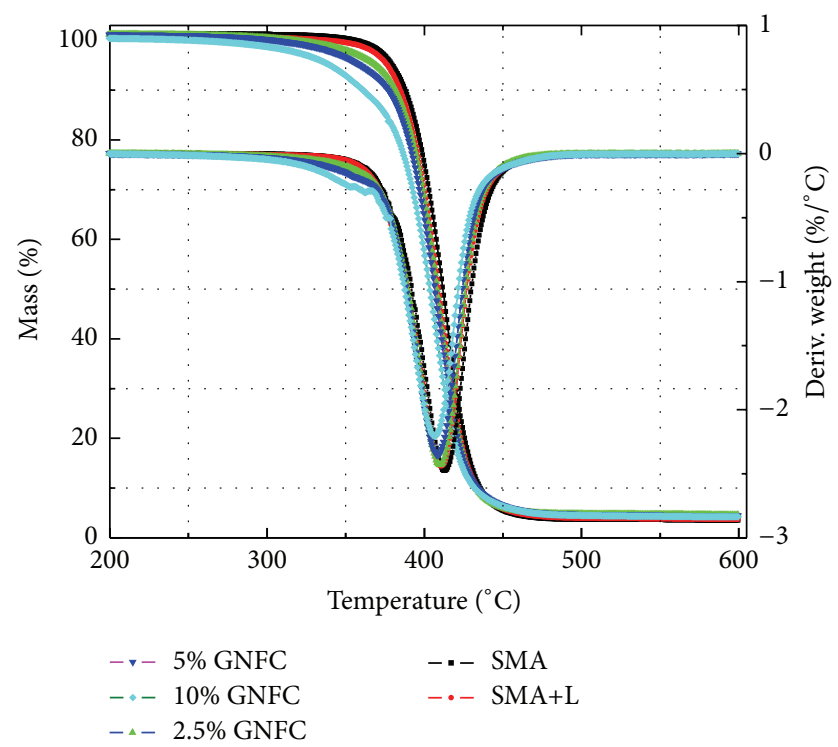

FIGURE 2: TGA and derivative TGA curves of SMA copolymer and GNFC composites.

are affected by GNFC loading and GNFC orientation and less by the SMA copolymer-GNFC interaction [44].

3.2. Thermogravimetric Analysis (TGA). The TGA and derivative TGA (DTGA) curves for the SMA copolymer and GNFC composites are presented in Figure 2. The SMA copolymer and 2.5 and 5\% GNFC composites undergo a single-stage degradation with a peak around $410^{\circ} \mathrm{C}$, whereas the $10 \%$ GNFC composites show two degradation peaks in the range of 355 to $406^{\circ} \mathrm{C}$. The temperature at $5 \%$ weight loss $\left(T_{5}\right)$ and the temperature at $50 \%$ weight loss $\left(T_{50}\right)$ for the SMA copolymer and GNFC composites are shown in Figure 3. Both $T_{5}$ and $T_{50}$ values for the composites decreased monotonically from the SMA copolymer to $10 \mathrm{wt} . \%$ GNFC addition. The results also show that the thermal stability of the composites decreased slightly as the GNFC content increased because of the lower thermal stability of GNFC compared to the SMA copolymer. The SMA copolymer shows slightly better thermal stability in comparison with lubricant modified SMA copolymer. In this study, lubricant was used to improve extrusion processing. It is also known that glycerine starts to evaporate at $200^{\circ} \mathrm{C}$ and fully evaporates at $300^{\circ} \mathrm{C}[45]$.

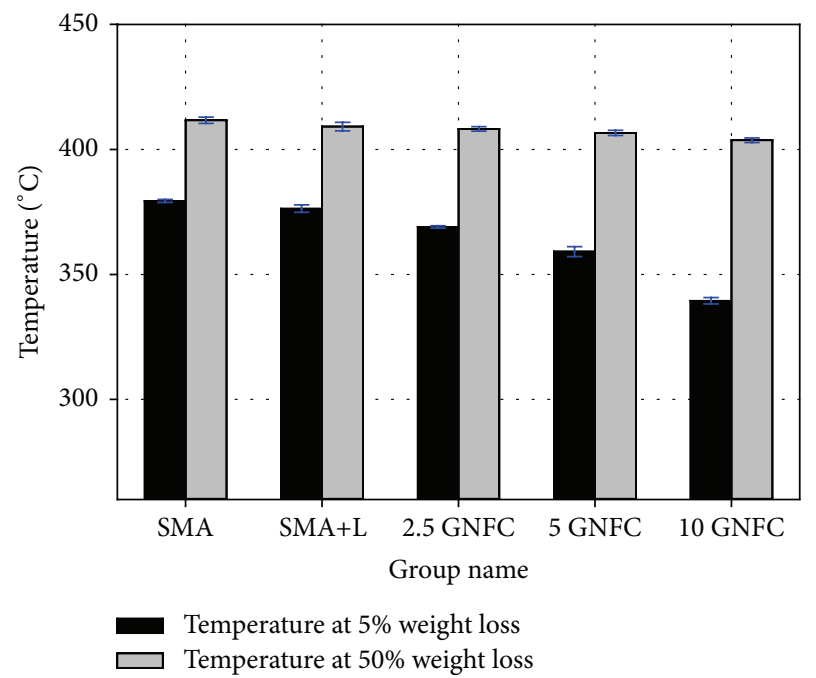

Figure 3: Temperatures at 5\% and 50\% weight loss for SMA copolymer and GNFC composites.

Therefore, the addition of glycerine may decrease thermal decomposition of NFC and this lower thermal stability of GNFC can limit the processing temperature of GNFC in SMA copolymer. The higher processing temperature of SMA resulted in lower mechanical properties that could also be explained by the thermal decomposition of GNFC. A summary of DTGA peak temperature, weight loss (WL) at DTGA peak temperature, and residual weight after $600^{\circ} \mathrm{C}$ of the composites is given in Table 3 .

3.3. Rheological Properties. The decomposition temperature of SMA copolymer and GNFC composites was higher than $250^{\circ} \mathrm{C}$ as determined by TGA in Figure 2 . Hence, the melt rheological measurements for SMA copolymer and GNFC composites were carried out at $240^{\circ} \mathrm{C}$. The elastic modulus $\left(G^{\prime}\right)$ for SMA copolymer and GNFC reinforced composites as function of frequency $(\omega)$ are shown in Figure 4. It is clear that GNFC has a distinct effect on $G^{\prime}$ of the SMA copolymer matrix, even at small loading level (2.5 wt.\%). The values of $G^{\prime}$ of GNFC reinforced SMA copolymer composites were significantly increased with GNFC content at lower frequencies because of the intrinsic rigidity of GNFC; the elastic modulus of composites is higher than the neat matrix, 
TABLE 3: Thermogravimetric data for SMA copolymer and GNFC composites.

\begin{tabular}{|c|c|c|c|}
\hline Sample code & DTGA peak temp. $\left({ }^{\circ} \mathrm{C}\right)$ & WL at DTGA peak temp. (\%) & Residue (\%) \\
\hline SMA & $412.9(0.3)$ & $51.2(0.2)$ & $3.6(0.7)$ \\
\hline $\mathrm{SMA}+\mathrm{L}$ & $410.8(0.2)$ & $52.9(0.7)$ & $3.8(0.3)$ \\
\hline 2.5\% GNFC & $409.9(0.5)$ & $53.3(0.5)$ & $4.6(0.2)$ \\
\hline $5 \%$ GNFC & $408.5(0.2)$ & $55.4(0.6)$ & $4.5(0.3)$ \\
\hline $10 \%$ GNFC & 2nd peak: $406.5(0.2)$ & 2nd peak: $57.5(0.4)$ & $4.3(0.2)$ \\
\hline
\end{tabular}

Parenthesis indicates standard deviation.

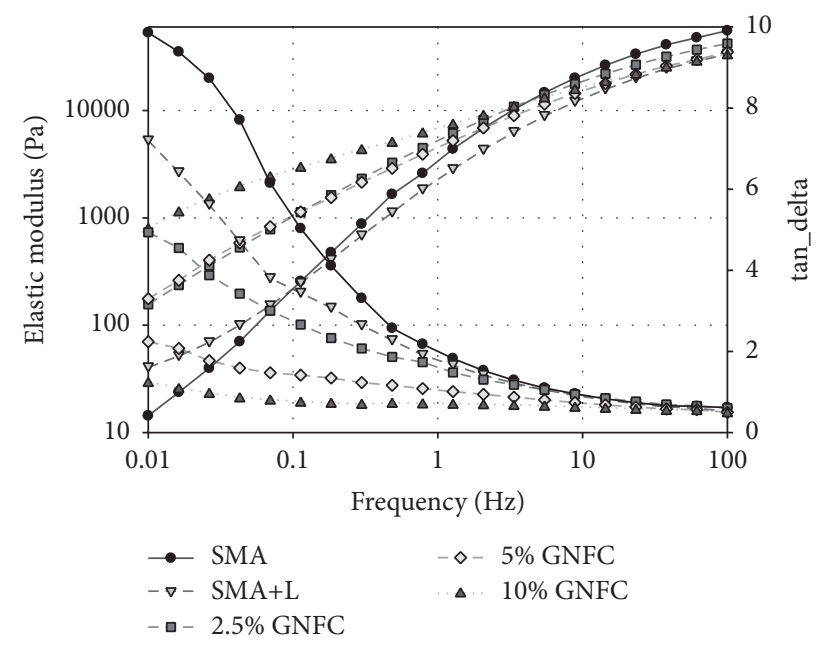

FIGURE 4: Storage modulus and tan_delta of the melt samples as a function of frequency.

especially for the highest GNFC loading level, indicating that stress transfers from the matrix to the treated NFC [46].

In Figure 4, the slope of the elastic modulus' curves decreased with increasing amounts of GNFC and the decrease in the slope can be explained by the microstructural changes with incorporation of GNFC. The GNFC-GNFC, which increase with increasing GNFC content in the polymer matrix, cause the formation of the interconnected or network-like structures of GNFC in the polymer composites. Because elastic modulus data serve as a measure of molecular rigidity, it can be concluded that, with the addition of the GNFC, the samples become more rigid: for comparison, at $\omega=0.01$ and $1 \mathrm{~Hz}$, the elastic modulus of SMA copolymer$10 \%$ GNFC is up to 55 and 2 times higher than that of the neat SMA copolymer, respectively. It is also evident from Figure 4 that SMA copolymer composites undergo a transition from liquid-like to solid-like viscoelasticity with an increase in GNFC loading in the low frequency region. In contrast, the effect of the nanofibers on the rheological behavior is relatively weak at high frequencies, as shown in Figure 4, suggesting that GNFC has a substantial influence on largescale polymer chain relaxations but has little effect on shortrange motion of polymer chains $[47,48]$. Figure 4 also shows the variation of tan_delta (loss modulus/elastic modulus) with frequency for the SMA copolymer composites and the tan_delta decreases with increasing the GFNC loading. This reduction is more noticeable at low $\omega$ (less than $1 \mathrm{~Hz}$ ) and can

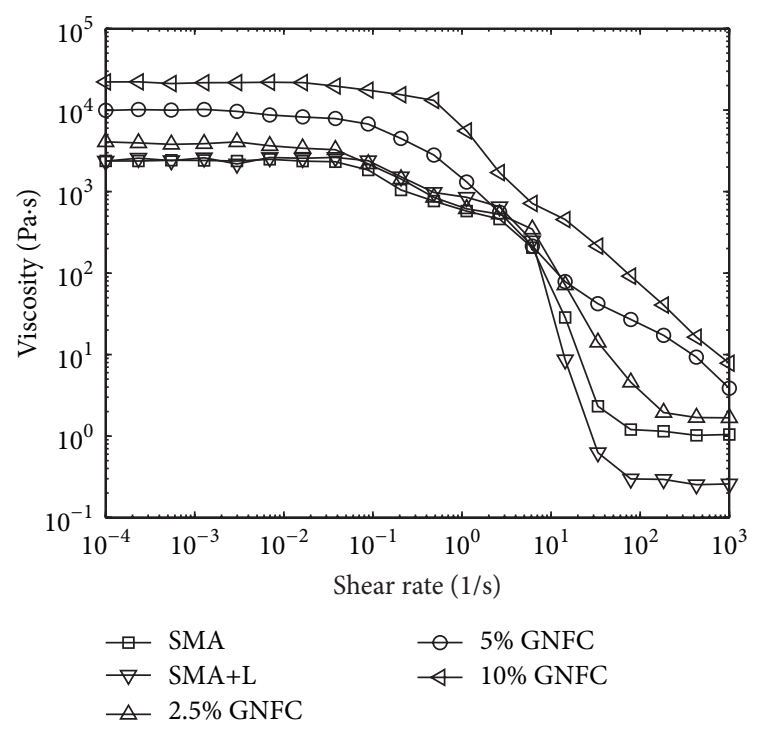

FIGURE 5: Steady-state shear viscosity of the melt samples as a function of shear rate.

be explained by improved elastic properties by introducing GNFC into SMA copolymer matrix and the changes in the microstructure and the formation of network structure in the composites [48, 49]. Figure 5 depicts the variation of melt viscosity as a function of shear rate at $240^{\circ} \mathrm{C}$ for the SMA copolymer and GNFC composites. It was found that the SMA composites behave as pseudoplastic fluids. The higher the GNFC content of the composite, the higher the shear viscosity and this behavior is attributed to the hindering of the movement of the macromolecular chains of the matrix by the GNFC [50]. The importance of the pseudoplastic behavior is greater as the GFNC content in the composite increases. Thus, the higher the amount of GNFC, the poorer the dispersion of the GNFC in the melt and the higher the viscosity of the filled polymer $[46,50]$. For the composite samples with 5 and $10 \mathrm{wt.} \%$ GNFC, the plateau at high shear rates was not observed in the applied shear rate range which may indicate that the shear rate is not high enough for the microstructure in these samples to break down. Figure 5 also shows that there are rapid drops on viscosity values at high shear rates. There is lack of information about rheological properties of SMA copolymer matrix in the literature. Further investigation is needed to fully understand rheological properties of GNFC reinforced SMA copolymer composites. 


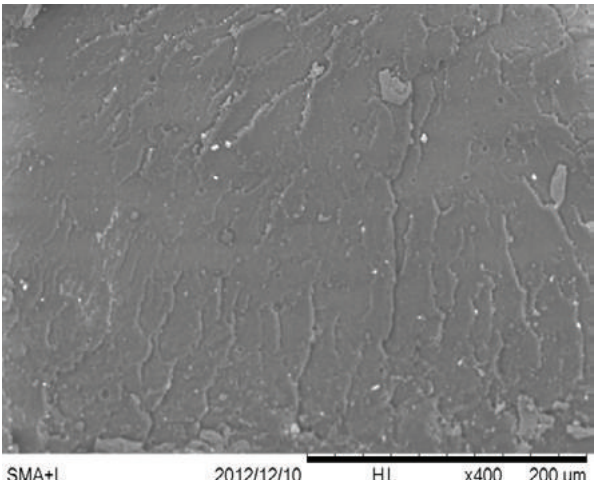

(a)

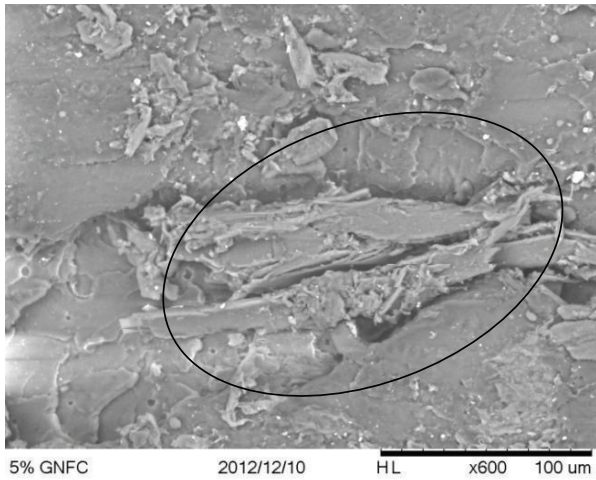

(c)

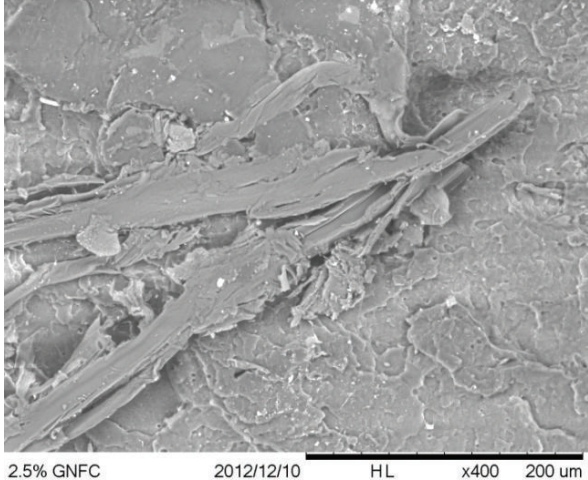

(b)

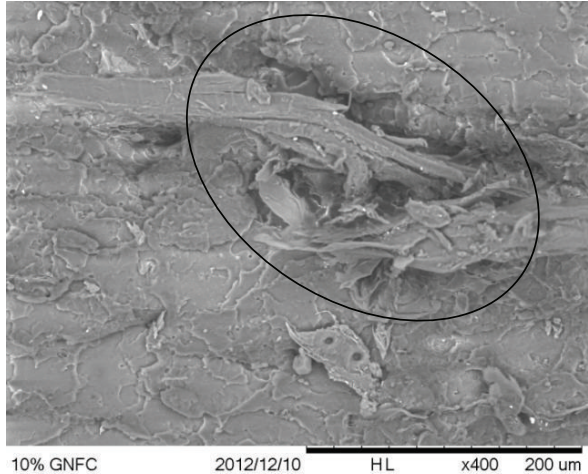

(d)

FIGURE 6: Overview of fractured composite surfaces: (a) SMA copolymer with lubricant, (b) $2.5 \%$ GNFC, (c) 5\% GNFC, and (d) $10 \%$ GNFC filler loading.

Table 2 also shows the MFI values for the SMA copolymer and GNFC treated composites. The incorporation of treated NFC reduced the flowability of SMA copolymer, which can increase the elastic modulus of a composite or the viscosity of a fluid suspension [51]. The MFI also decreased with increasing treated GNFC loading because of the incorporation of rigid GNFC weight to the SMA copolymer matrices restricting the composites free mobility and increasing the material viscosity [51]. The MFI value of the neat SMA copolymer was $5.1 \mathrm{~g} / 10 \mathrm{~min}$ and decreased to $0.3 \mathrm{~g} / 10 \mathrm{~min}$ (10 wt.\% GNFC content, decreased 95.1\%). Similar results were also reported by Teng et al. for multiwalled carbon nanotube/polypropylene composites [52]. SMA copolymerGNFC formulations did not present significant problems during the injection molding process; however, some small adjustments of the processing conditions may be necessary to make products with a GNFC content of more than $20 \mathrm{wt} . \%$, especially increasing the injection pressure [53]. Adding lubricant to the matrix made a slight decrease in elastic modulus at all frequencies reflecting that the stiffness of the polymer decreased by adding a low molecular weight material. Similarly, the addition of lubricant decreased melt viscosity of composites at all shear rates and increased flowability of the SMA copolymer. In this study, lubricant was used only as an additive to improve processing conditions.
The results of TMOE and FMOE are in accordance with the rheological data. Because of the intrinsic rigidity of GNFC, the TMOE and FMOE are higher than SMA copolymer, especially for the highest GNFC content (10 wt.\%). Increasing the modulus of elasticity of composites compared with the matrix polymer can also be associated with the restrictions of macromolecules mobility and deformability imposed by the presence of GNFC. The presence of GNFC perturbs normal polymer flow and restricts the mobility of chain segments. Thus, the higher the amount of GNFC, the lower the MFI or the higher the viscosity of the filled polymer [46].

3.4. Morphological Properties. SEM micrographs of the fractured surfaces of the SMA copolymer and GNFC composites are shown in Figure 6. The aim was to investigate if any GNFC aggregates were visible on the impact fracture surfaces.

As expected, because of the presence of polar groups, it is likely that SMA copolymer chains adhere to GNFC via esterification reactions between NFC and maleic anhydride on the SMA and the attraction between GNFC and SMA copolymer may also make dispersion of the GNFC within the matrix more effective. However, the image shows areas which are attributed to fiber bundles in all samples (Figures 6(b)-6(d)) indicating that mixing was not complete at the level of individual fibers. It appears that all the images 
showed evidence of aggregation of GNFC fibers and generally poor adhesion between the GNFC surface and the SMA copolymer matrix. In other words, glycerine was not efficient to disperse the NFC within the SMA copolymer matrix. Similar results were also reported by Simonsen et al. for wood fiber-reinforced SMA copolymer composites [28]. To gain a better understanding of interface between SMA copolymer and GNFC as well as the need for addition of coupling agents or surface modification of NFC surface to improve properties, techniques such as nanoindentation and microbond testing methods could be employed [54].

\section{Conclusions}

Mechanical properties, thermal stability, melt rheology, and morphological behavior of SMA copolymer and composites with various GNFC loadings were studied in this work. The SMA composites reinforced with GNFC displayed higher tensile and flexural modulus of elasticity; however, the tensile and flexural strength and elongation at break of the composites decreased compared to the neat SMA copolymer matrix. The thermal stability of the composites decreased slightly as GNFC content increased because of the lower thermal stability of GNFC compared to the SMA copolymer. The $\tan \delta$ decreased noticeably with increasing the GFNC loading at lower frequencies. It was found that the incorporation of GNFC in a SMA copolymer matrix results in higher elastic modulus and shear viscosities compared to those of neat SMA copolymer, especially in the low frequency region. With an increase in GNFC loading, the composites experienced a transition from liquid-like to solid-like viscoelasticity and strong shear thinning behavior was observed in the composites. SEM micrographs showed that glycerine was not efficient to disperse the NFC within the SMA copolymer matrix. The results of TMOE and FMOE are in accordance with the rheological data for SMA/GNFC composites.

\section{Disclosure}

This is the 3468th paper of the Maine Agricultural and Forest Experiment Station.

\section{Competing Interests}

The authors declare that they have no competing interests regarding the publication of this paper.

\section{Acknowledgments}

The authors would like to acknowledge the contributions of Alex Nash and Chris West whose hard work made this paper possible. The authors would also like to thank Maine Agricultural and Forest Experiment Station Project ME09615-08MS and the Wood Utilization Research Hatch 2007-2008 Project.

\section{References}

[1] L. Tang and C. Weder, "Cellulose whisker/epoxy resin nanocomposites," ACS Applied Materials \& Interfaces, vol. 2, no. 4, pp. 1073-1080, 2010.

[2] S. J. Eichhorn, A. Dufrense, M. Arunguren et al., "Review: current international research into cellulosic fibres and composites," Journal of Material Science, vol. 36, no. 9, pp. 2107-2131, 2010.

[3] I. Siró and D. Plackett, "Microfibrillated cellulose and new nanocomposite materials: a review," Cellulose, vol. 17, no. 3, pp. 459-494, 2010.

[4] S. Kalia, A. Dufresne, B. M. Cherian et al., "Cellulose-based bioand nanocomposites: a review," International Journal of Polymer Science, vol. 2011, Article ID 837875, 35 pages, 2011.

[5] D. Klemm, F. Kramer, S. Moritz et al., "Nanocelluloses: a new family of nature-based materials," Angewandte ChemieInternational Edition, vol. 50, no. 24, pp. 5438-5466, 2011.

[6] R. J. Moon, A. Martini, J. Nairn, J. Simonsen, and J. Youngblood, "Cellulose nanomaterials review: structure, properties and nanocomposites," Chemical Society Reviews, vol. 40, no. 7, pp. 3941-3994, 2011.

[7] B. L. Peng, N. Dhar, H. L. Liu, and K. C. Tam, "Chemistry and applications of nanocrystalline cellulose and its derivatives: a nanotechnology perspective," The Canadian Journal of Chemical Engineering, vol. 89, no. 5, pp. 1191-1206, 2011.

[8] H. P. S. Abdul Khalil, A. H. Bhat, and A. F. Ireana Yusra, "Green composites from sustainable cellulose nanofibrils: a review," Carbohydrate Polymers, vol. 87, no. 2, pp. 963-979, 2012.

[9] H. Charreau, M. L. Foresti, and A. Vázquez, "Nanocellulose patents trends: a comprehensive review on patents on cellulose nanocrystals, microfibrillated and bacterial cellulose," Recent Patents on Nanotechnology, vol. 7, no. 1, pp. 56-80, 2013.

[10] N. Duran, A. P. Lemes, and A. B. Seabra, "Review of cellulose nanocrystals patents: preparation, composites and general applications," Recent Patents Nanotechnolgy, vol. 6, no. 1, pp. 1628, 2012.

[11] N. Lavoine, I. Desloges, A. Dufresne, and J. Bras, "Microfibrillated cellulose-its barrier properties and applications in cellulosic materials: a review," Carbohydrate Polymers, vol. 90, no. 2, pp. 735-764, 2012.

[12] J. K. Pandey, A. N. Nakagaito, and H. Takagi, "Fabrication and applications of cellulose nanoparticle-based polymer composites," Polymer Engineering and Science, vol. 53, no. 1, pp. 1-8, 2013.

[13] A. Abbott and A. Bismarck, "Self-reinforced cellulose nanocomposites," Cellulose, vol. 17, no. 4, pp. 779-791, 2010.

[14] C. Eyholzer, N. Bordeanu, F. Lopez-Suevos, D. Rentsch, T. Zimmermann, and K. Oksman, "Preparation and characterization of water-redispersible nanofibrillated cellulose in powder form," Cellulose, vol. 17, no. 1, pp. 19-30, 2010.

[15] Y. Habibi, L. A. Lucia, and O. J. Rojas, "Cellulose nanocrystals: chemistry, self-assembly, and applications," Chemical Reviews, vol. 110, no. 6, pp. 3479-3500, 2010.

[16] M. Jonoobi, J. Harun, A. P. Mathew, M. Z. B. Hussein, and K. Oksman, "Preparation of cellulose nanofibers with hydrophobic surface characteristics," Cellulose, vol. 17, no. 2, pp. 299-307, 2010.

[17] T. Abitbol, T. Johnstone, T. M. Quinn, and D. G. Gray, "Reinforcement with cellulose nanocrystals of poly(vinyl alcohol) hydrogels prepared by cyclic freezing and thawing," Soft Matter, vol. 7, no. 6, pp. 2373-2379, 2011. 
[18] J.-F. Sassi and H. Chanzy, "Ultrastructural aspects of the acetylation of cellulose," Cellulose, vol. 2, no. 2, pp. 111-127, 1995.

[19] C. Goussé, H. Chanzy, M. L. Cerrada, and E. Fleury, "Surface silylation of cellulose microfibrils: preparation and rheological properties," Polymer, vol. 45, no. 5, pp. 1569-1575, 2004.

[20] M. Andresen, L.-S. Johansson, B. S. Tanem, and P. Stenius, "Properties and characterization of hydrophobized microfibrillated cellulose," Cellulose, vol. 13, no. 6, pp. 665-677, 2006.

[21] T. Saito, Y. Nishiyama, J.-L. Putaux, M. Vignon, and A. Isogai, "Homogeneous suspensions of individualized microfibrils from TEMPO-catalyzed oxidation of native cellulose," Biomacromolecules, vol. 7, no. 6, pp. 1687-1691, 2006.

[22] P. Stenstad, M. Andresen, B. S. Tanem, and P. Stenius, "Chemical surface modifications of microfibrillated cellulose," Cellulose, vol. 15, no. 1, pp. 35-45, 2008.

[23] J. Kim, G. Montero, Y. Habibi et al., "Dispersion of cellulose crystallites by nonionic surfactants in a hydrophobic polymer matrix," Polymer Engineering and Science, vol. 49, no. 10, pp. 2054-2061, 2009.

[24] A. Kiziltas, B. Nazari, E. Erbas Kiziltas, D. J. Gardner, Y. Han, and T. S. Rushing, "Method to reinforce polylactic acid with cellulose nanofibers via a polyhydroxybutyrate carrier system," Carbohydrate Polymers, vol. 140, pp. 393-399, 2016.

[25] A. Kiziltas, B. Nazari, E. E. Kiziltas, D. J. Gardner, Y. Han, and T. S. Rushing, "Cellulose NANOFIBER-polyethylene nanocomposites modified by polyvinyl alcohol," Journal of Applied Polymer Science, vol. 133, no. 6, 2016.

[26] A. Dorris and D. G. Gray, "Gelation of cellulose nanocrystal suspensions in glycerol," Cellulose, vol. 19, no. 3, pp. 687-694, 2012.

[27] J. Simonsen, R. Jacobson, and R. Rowell, "Properties of styrenemaleic anhydride copolymers containing wood-based fillers," Forest Products Journal, vol. 48, no. 1, pp. 89-92, 1998.

[28] J. Simonsen, R. Jacobsen, and R. Rowell, "Wood-fiber reinforcement of styrene-maleic anhydride copolymers," Journal of Applied Polymer Science, vol. 68, no. 10, pp. 1567-1573, 1998.

[29] A. Sarı, C. Alkan, A. Karaipekli, and A. Önal, "Preparation, characterization and thermal properties of styrene maleic anhydride copolymer (SMA)/fatty acid composites as form stable phase change materials," Energy Conversion and Management, vol. 49, no. 2, pp. 373-380, 2008.

[30] A. R. Bhattacharyya, P. Pötschke, M. Abdel-Goad, and D. Fischer, "Effect of encapsulated SWNT on the mechanical properties of melt mixed PA12/SWNT composites," Chemical Physics Letters, vol. 392, no. 1-3, pp. 28-33, 2004.

[31] A. R. Bhattacharyya, S. Bose, A. R. Kulkami et al., "Styrene maleic anhydride copolymer mediated dispersion of single wall carbon nanotubes in polyamide 12: crystallization behavior and morphology," Journal of Applied Polymer Science, vol. 106, no. 1, pp. 345-353, 2007.

[32] G. Wang, Z. Qu, L. Liu, Q. Shi, and J. Guo, "Study of SMA graft modified MWNT/PVC composite materials," Materials Science and Engineering A, vol. 472, no. 1-2, pp. 136-139, 2008.

[33] A. Chrysostomou and S. Hashemi, "Mechanical properties of injection moulded styrene maleic anhydride (SMA): part II influence of short glass fibres and weldlines," Journal of Materials Science, vol. 33, no. 18, pp. 4491-4501, 1998.

[34] A. Chrysostomou and S. Hashemi, "Mechanical properties of injection-moulded styrene maleic anhydride (SMA): part I: influence of weldline and reprocessing," Journal of Materials Science, vol. 33, no. 5, pp. 1165-1175, 1998.
[35] Y. Han and D. J. Gardner, "Foamed styrene-based WPC using physical blowing agent created during reactive extrusion," in Proceedings of 10th International Conference on Wood \& Biofiber Plastic Composites, Proceedings no. 7218-09, pp. 27-35, Forest Products Society, 2010.

[36] S. Michalik, D. J. Gardner, C. H. West, and Y. Han, "Method of making cellulosic filled thermoplastic composites of an anhydride containing copolymer," Patent No: US 8221663, 2012.

[37] A. Kiziltas, D. J. Gardner, Y. Han, and H.-S. Yang, "Mechanical Properties of Microcrystalline Cellulose (MCC) filled engineering thermoplastic composites," Journal of Polymers and the Environment, vol. 22, no. 3, pp. 365-372, 2014.

[38] D. Aydemir, A. Kiziltas, E. Erbas Kiziltas, D. J. Gardner, and G. Gunduz, "Heat treated wood-nylon 6 composites," Composites Part B: Engineering, vol. 68, pp. 414-423, 2015.

[39] D. Aydemir, A. Kiziltas, D. J. Gardner, Y. Han, and G. Gunduz, "Thermal analysis of micro- and nano-lignocellulosic reinforced styrene maleic anhydride composite foams," International Journal of Polymer Analysis and Characterization, vol. 20, no. 3, pp. 231-239, 2015.

[40] E. Ozen, A. Kiziltas, E. E. Kiziltas, and D. J. Gardner, "Natural fiber blend-nylon 6 composites," Polymer Composites, vol. 34, no. 4, pp. 544-553, 2013.

[41] SAS Institute, JMP Statistical Discovery Software, Version 8, SAS Institute, Cary, NC, USA, 2008.

[42] P. Qu, Y. Gao, G.-F. Wu, and L.-P. Zhang, "Nanocomposites of poly(lactic acid) reinforced with cellulose nanofibrils," BioResources, vol. 5, no. 3, pp. 1811-1823, 2010.

[43] D. I. Munthoub and W. A. W. A. Rahman, "Tensile and water absorption properties of biodegradable composites derived from cassava skin/polyvinyl alcohol with glycerol as plasticizer," Sains Malaysiana, vol. 40, no. 7, pp. 713-718, 2011.

[44] M. Bengtsson and K. Oksman, "The use of silane technology in crosslinking polyethylene/wood flour composites," Composites Part A: Applied Science and Manufacturing, vol. 37, no. 5, pp. 752-765, 2006.

[45] M. Z. B. Yunos and W. A. W. A. Rahman, "Effect of glycerol on performance Rice Straw/Starch Based Polymer," Journal of Applied Sciences, vol. 11, no. 13, pp. 2456-2459, 2011.

[46] D. Shumigin, E. Tarasova, A. Krumme, and P. Meier, "Rheological and mechanical properties of poly(lactic) acid/cellulose and LDPE/cellulose composites," Materials Science, vol. 17, no. 1, pp. 32-37, 2011.

[47] C. A. Mitchell, J. L. Bahr, S. Arepalli, J. M. Tour, and R. Krishnamoorti, "Dispersion of functionalized carbon nanotubes in polystyrene," Macromolecules, vol. 35, no. 23, pp. 8825-8830, 2002.

[48] M. Wang, W. Wang, T. Liu, and W.-D. Zhang, "Melt rheological properties of nylon 6/multi-walled carbon nanotube composites," Composites Science and Technology, vol. 68, no. 12, pp. 2498-2502, 2008.

[49] H. Azizi and I. Ghasemi, "Investigation on the dynamic melt rheological properties of polypropylene/wood flour composites," Polymer Composites, vol. 30, no. 4, pp. 429-435, 2009.

[50] C. González-Sánchez, C. Fonseca-Valero, A. Ochoa-Mendoza, A. Garriga-Meco, and E. Rodríguez-Hurtado, "Rheological behavior of original and recycled cellulose-polyolefin composite materials," Composites Part A: Applied Science and Manufacturing, vol. 42, no. 9, pp. 1075-1083, 2011.

[51] D. S. Rosa, C. G. F. Guedes, and C. L. Carvalho, "Processing and thermal, mechanical and morphological characterization of 
post-consumer polyolefins/thermoplastic starch blends," Journal of Materials Science, vol. 42, no. 2, pp. 551-557, 2007.

[52] C.-C. Teng, C.-C. M. Ma, Y.-W. Huang et al., "Effect of MWCNT content on rheological and dynamic mechanical properties of multiwalled carbon nanotube/polypropylene composites," Composites Part A: Applied Science and Manufacturing, vol. 39, no. 12, pp. 1869-1875, 2008.

[53] S. Chen, H. Li, F. Wang, and Y. Zhang, "Experimental study on injection molding of wheat-straw/HDPE composites," in Proceedings of the Annual Conference of the Society of Plastics Engineers (ANTEC '11), pp. 1-6, Boston, Mass, USA, 2011.

[54] E. McHenry and Z. H. Stachurski, "Composite materials based on wood and nylon fibre," Composites Part A: Applied Science and Manufacturing, vol. 34, no. 2, pp. 171-181, 2003. 

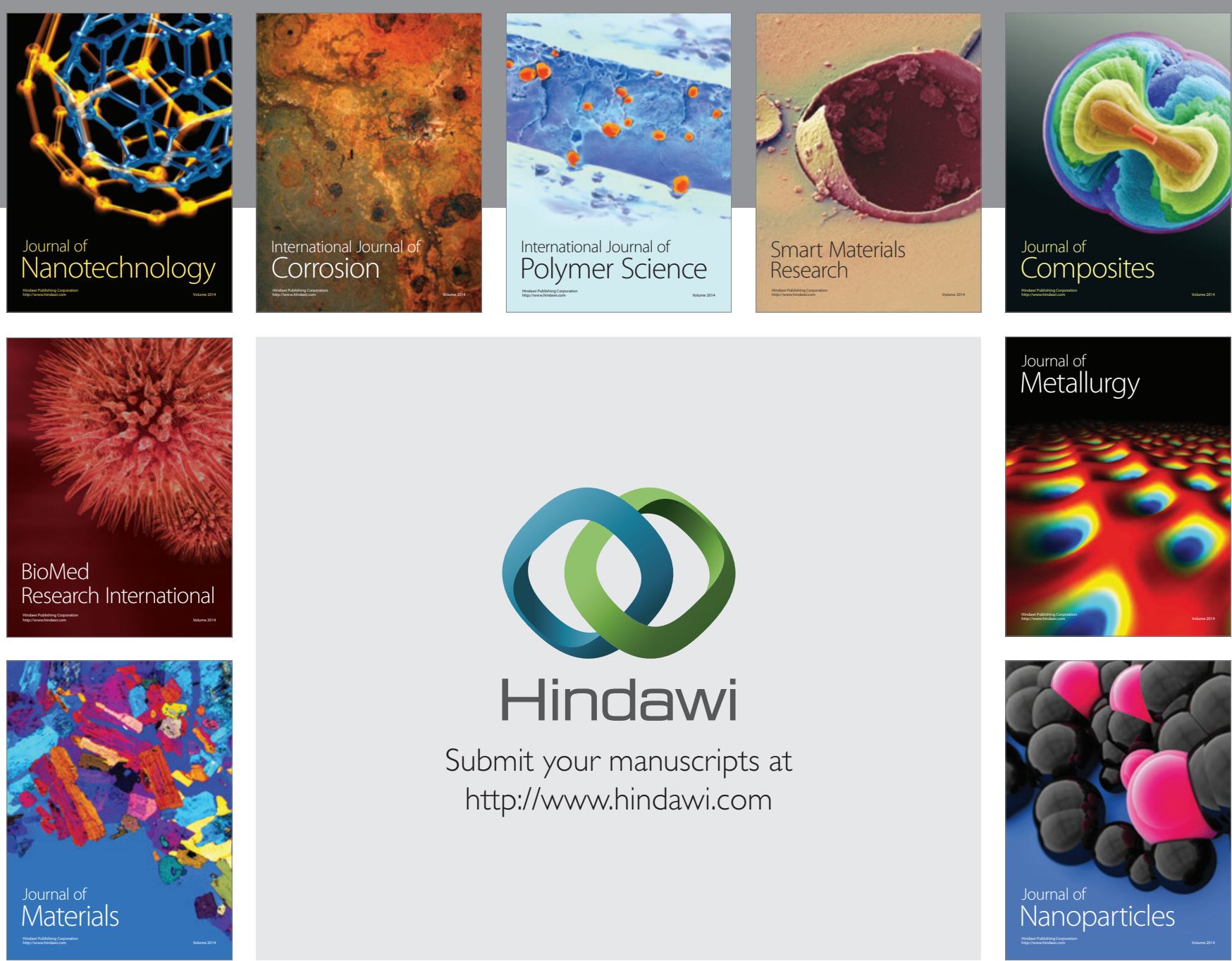

\section{Hindawi}

Submit your manuscripts at

http://www.hindawi.com

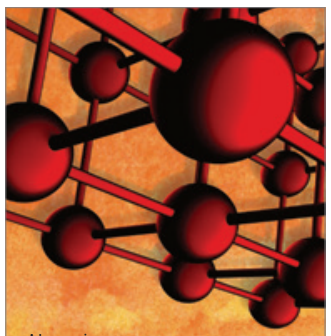

Materials Science and Engineering
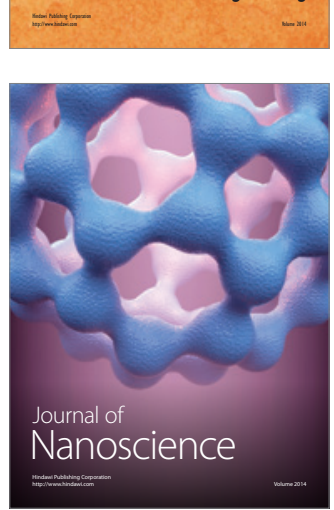
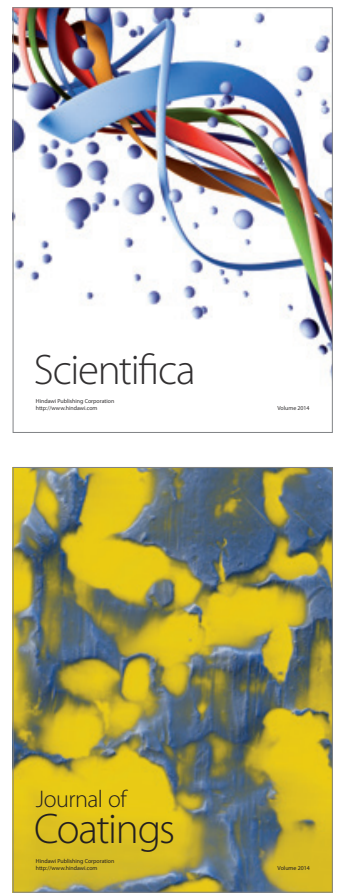
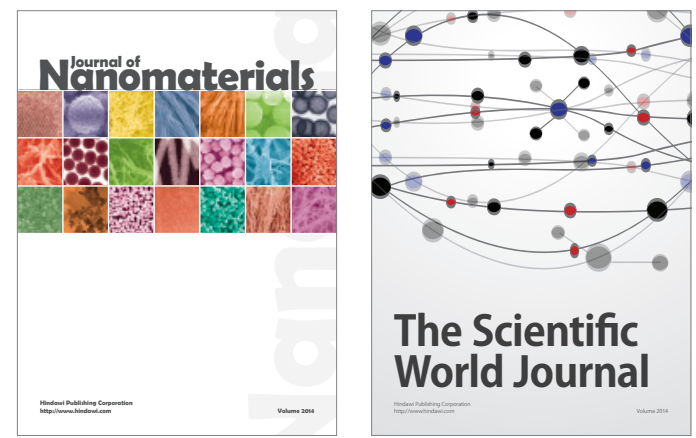

The Scientific World Journal
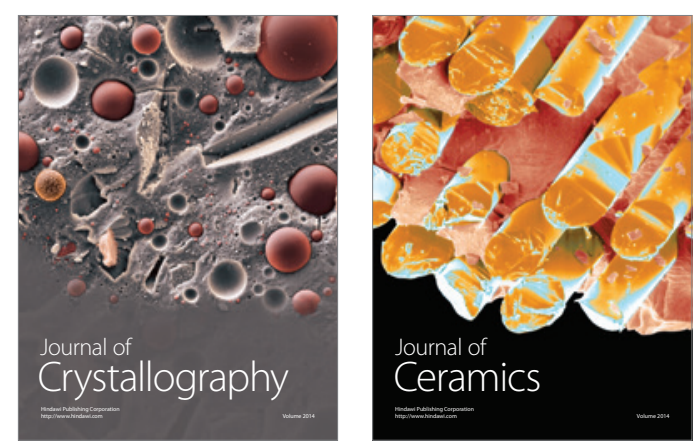
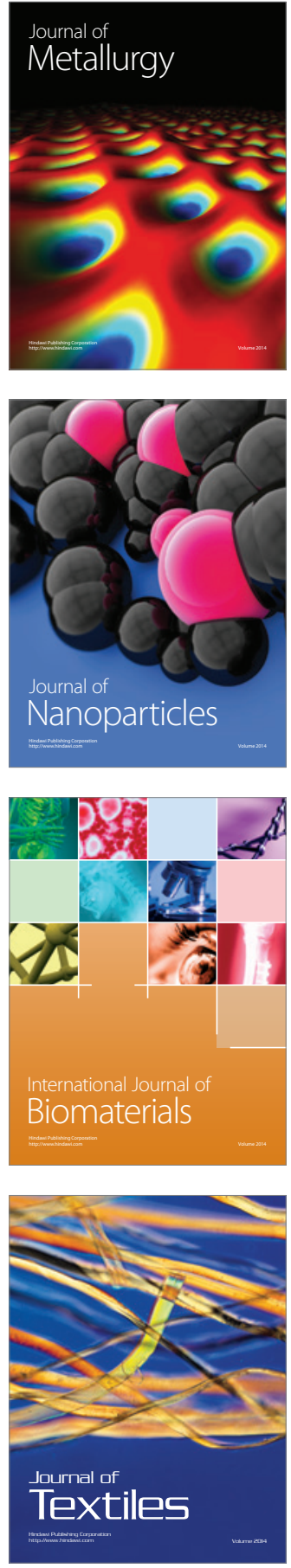